\title{
Physical Activity and Wellbeing Advancing Practices in Female Physiotherapy Students of the University of Lahore
}

\author{
Fahad Tanveer ${ }^{1}$, Sana Shahid ${ }^{2}$ \\ ${ }^{1}$ Senior Lecturer, Azra Naheed Medical College, Department of Physical Therapy, Main Raiwind Road, Lahore \\ ${ }^{2}$ Demonstrator, The University of Lahore, Department of Physical Therapy, Main Raiwind Road, Lahore
}

\begin{abstract}
Physical action lessens the danger of numerous wellbeing conditions. Females are less physical dynamic when contrasted with male. Numerous scientists reasoned that females had undesirable way of life. Wellbeing advancing conduct portrays the wellbeing status of a man. Sound conduct advances the personal satisfaction. The target of this study was to decide the level of physical movement and wellbeing advancing practices of Female Physiotherapy Understudies of The College of Lahore. Auxiliary target of this study was to discover the relationship between physical movement and wellbeing advancing practices. Study design was associational analytical study. Research will be conducted at The University of Lahore. The Sample size of this research was 158.Simple randomized sampling technique was used for sample selection. Out of 858 females 158 fulfilling the inclusion criteria were selected randomly from all departments of The University of Lahore. Rapid assessment of physical activity tool was used to check the level of physical activity Health-promoting life style profile-II scale was used to measure the health promoting behaviours. $8(5.1 \%)$ females scored as sedentary lifestyle and 70 (44.4\%) females scored as active on Rapid assessment of physical activity-I The mean value of Rapid assessment of physical activity-I was 4.74(SD=1.893) which was less than 6 it showed female had suboptimal level of physical activity. The Mean value of Health promoting lifestyle profile-II was 2.41(SD=.404). which labeled as low. Out of 6 subscales of health promoting lifestyle profile, Spiritual growth scored maximum Mean value $2.57(S D=.558)$ while Health responsibility scored lowest value $2.21(S D=.471)$. The $R$ was $.065(p=0.41)$ that showed a weak correlation between level of physical activity and health promoting practices. This study reasoned that Female Physiotherapy Understudies were less physically dynamic. They had unfortunate way of life. Wellbeing advancing conduct likewise scored as low. Wellbeing advancing practices had no impact on physical action level of females.
\end{abstract}

Keywords: female, health promoting behavior, physical activity, medical student, unhealthy lifestyle

\section{Introduction}

\subsection{Overview}

Wellbeing advancing practices assume an essential part in deciding the of wellbeing status of people. The hidden reason for a large portion of the wellbeing related issues of youngsters is ascribed to the wellbeing trading off practices as per the Worldwide Relationship for youthful wellbeing. Youthful people are the future and a noteworthy resource of their families, groups and countries. Nowadays, the majority of the youthful people are enjoyed wellbeing trading off practices like unseemly sustenance, absence of physical action, tobacco and medication misuse, exorbitant caffeine allow, all of which effectsly affect the wellbeing.(1)

Consistent physical action diminishes the danger of numerous therapeutic conditions and enhances the prosperity of a person.The World Wellbeing Association (WHO) expresses that diminished physical action is the greatest reasons for mortality and debilitation and a major reason for some genuine conditions, for example, hypertension, diabetes and overweight. Numerous proofs demonstrate that physical action level among young ladies is controlled by wellbeing convictions, social and mental condition, and selfviability.(2)

School life is a period of an individual's life in which he/she is presented to push, absence of time for self, prompting less consideration towards a solid way of life. Inferable from the troublesome educational programs and long length study period restorative Physiotherapy Understudies have been found to give less consideration towards a sound way of life regardless of an unrivaled information of wellbeing elevating propensities when contrasted with non-therapeutic Physiotherapy Understudies.(3) As indicated by the young danger conduct review of Joined States (2013) the majority of the secondary schools Physiotherapy Understudies are occupied with practices that put them at wellbeing related dangers. The pervasiveness of wellbeing trading off practices has been observed to be higher in females when contrasted with guys.(4)

Wellbeing trading off ways of life of the youthful females have been observed to be connected with a craving to be physically thin. (5) Wellbeing status of youthful females is vital as it will impact their wellbeing status in the later years of life because of physical and physiological changes. Wellbeing advancing practices strongly affect the long haul wellbeing results.

Proof proposes that the physical movement propensities and the wellbeing related practices of the restorative work force has an impact on their clinical states of mind towards Physical exercises and different qualities of wellbeing advancement.(6) The physical movement support data show that many people are either non ambitious, having no will to be all the more physically dynamic. Natural and extraneous inspirations are vital in measuring the results of their conduct and physical action.(7). 


\section{International Journal of Science and Research (IJSR) \\ ISSN (Online): 2319-7064}

Index Copernicus Value (2013): 6.14 | Impact Factor (2015): 6.391

Adolescent young men are more dynamic than youngster young ladies. . Reason is that there are change in the encompassing conditions and boundary as a component for females when contrasted with guys. These elements are vital to perform physical movement in females.(8)

A longitudinal study on the relationship of wellbeing practices and the body fulfillment in young people has demonstrated a lower body fulfillment connected with a more elevated amount of wellbeing bargaining practices and practices.(9)

A couple explores have been performed about physical action among females. For the most part relative considered has been performed. Past studies had concentrated on contemplating the wellbeing advancing or trading off practices and practices of young people and youngsters or for the most part college Physiotherapy Understudies. Physiotherapy Understudies and particularly female Physiotherapy Understudies have not been engaged upon. There was a need to discover the level of physical action and practices of youthful female Physiotherapy Understudies in regards to their own wellbeing advancement since wellbeing advancing practices had influence on their own wellbeing and in addition their directing capacities for the patients they would manage in future furthermore enhances the personal satisfaction among females.

\subsection{Objectives}

The objectives of this study were

- To determine the physical activity level and healthpromoting practices of Female Physiotherapy Students of The University of Lahore.

- To find out the association between level of physical activity and health-promoting practices of Females Physiotherapy Students of The University of Lahore.

\subsection{Rationale}

The rationale of the study is to aware the female physiotherapy students of university of Lahore about the importance of physical activity.

\subsubsection{BMI: Health-promoting lifestyle profile -II}

The wellbeing advancing way of life profile instrument was amended so as to empower the specialists to quantify the wellbeing advancing practices of people and to reinforce the substance legitimacy of the instrument. The Wellbeing advancing way of life profile-II was a 52-thing survey which comprises of six subscales i.e. profound development, interpersonal relations, nourishment, physical movement, wellbeing obligation and anxiety administration. Every thing on the scale must be numbered on a 4-point Likert scale where "1" indicates 'never', "2" for 'at times', "3" for "regularly" and "4" is set apart for 'routinely'. The mean scores for each subscale ascertained separately. The $\alpha$ coefficient for the inward consistency has been observed for the scale to be .943 and for subscales are 0.793 to 0.872 . The test-retest dependability is 0.892.(10)

\subsubsection{Rapid Assessment of Physical Activity}

Physical action is characterized as any substantial development created by skeletal muscle that requires vitality expenditure.(WHO).This scale is dependable to check the level of physical action among individuals. It has three sections Oxygen consuming, adaptability and quality level. Specificity and affectability of this scale is 0.75 and 0.73 individually. (11)

\subsection{Materials and methods}

\subsubsection{Study Design}

The present study is an Associational analytical study.

\subsubsection{Setting}

The study was conducted in The University of Lahore.

\subsubsection{Study Population}

Female students of The University of Lahore

\subsubsection{Duration of Study}

The study took 4 months from November 2014 to February 2015 after approval from advance research committee

\subsubsection{Sample size}

The sample size was calculated by the following formula keeping the power of study equal to $90 \%$ and level of significance equal to $5 \%$. The sample size should be 158 .

$\mathrm{x}=\mathrm{Z}(\mathrm{c} / 100) 2 \mathrm{r}(100-\mathrm{r})$

$\mathrm{n}=\mathrm{N} x /((\mathrm{N}-1) \mathrm{E} 2+\mathrm{x})$

$\mathrm{E}=\operatorname{Sqrt}[(\mathrm{N}-\mathrm{n}) \mathrm{x} / \mathrm{n}(\mathrm{N}-1)]$

$\mathrm{N}$ used for population Size, E for margin error, $\mathrm{Z}(\mathrm{c} / 100)$ is value for confidence level

\subsubsection{Eligibility}

1.4.6.1 Case group

Inclusion Criteria

Female Physiotherapy Students of the University of Lahore

\section{Exclusion Criteria}

- Systemic or pathological diseased females

- Females having any Recent surgery or history of trauma

- Females having psychological disorders i-e taking medicine for depression or stress.

- Females having any chronic illness

\section{- Married females}

\subsubsection{Data collection}

The study was conducted in The University of Lahore which has about 188 students enrolled in DPT at the start of study.19 students refused to participate in the study and 13 were not available during study duration. Remaining 158 were selected by simple random sampling using random number table who were matched in gender, residence status. The questionnaires were consisting of three parts. Part A was consist of a selfreport questionnaire in which Name, Age, Social status, Residential area, Height, Weight; Body mass index will be included. Part B was consisting of an instrument to measure the health-promoting practices of female Physiotherapy Students. The instrument was the Health-promoting life style profile-II, which was a validated tool to measure the health promoting behaviors. The content validity and test-retest reliability of the revised tool was high.(10) Part C consisted of Rapid assessment 


\section{International Journal of Science and Research (IJSR) \\ ISSN (Online): 2319-7064 \\ Index Copernicus Value (2013): 6.14 | Impact Factor (2015): 6.391}

of physical activity. This tool was valid to measure the level of physical activity.

\subsubsection{Ethical consideration}

The ethical committee and Department of Medical Education of The University of Lahore approved to conduct the study in the University. Only those students were included in the study who signed the written consent. All the personal information of participants were kept hidden

\subsubsection{Statistical Procedure}

The Data was analyzed using SPSS v20.Mean \pm SD was calculated for numeric variables i.e. Frequency, Mean and standard deviation was calculated for the health promoting lifestyle profile scale and rapid assessment of physical activity tool. Regression test was used to measure the correlation between health promoting practices and physical activity level. $\mathrm{P}$ value $\leq .05$ was considered statistically significant.

\section{Results}

\begin{tabular}{|c|c|c|c|}
\hline Variable & Construct & $\begin{array}{c}\text { Frequency } \\
(\mathrm{n}=158)\end{array}$ & $\begin{array}{c}\text { Percentages } \\
(\%)\end{array}$ \\
\hline \multirow{3}{*}{$\begin{array}{c}\text { Basal } \\
\text { Metabolic } \\
\text { Index }\end{array}$} & Underweight & 20 & 12.7 \\
\hline & Normal & 100 & 63.3 \\
\hline & Overweight & 38 & 24.1 \\
\hline \multirow{5}{*}{$\begin{array}{l}\text { Level of } \\
\text { Physical } \\
\text { activity }\end{array}$} & Sedentary & 8 & 5.1 \\
\hline & Under-active & 18 & 11.4 \\
\hline & $\begin{array}{c}\text { Under-active regular-light } \\
\text { activities }\end{array}$ & 18 & 11.4 \\
\hline & Underactive regular & 44 & 27.9 \\
\hline & Active & 70 & 44.4 \\
\hline \multirow{4}{*}{$\begin{array}{l}\text { Strenghth } \\
\text { and } \\
\text { Flexibility } \\
\text { Training }\end{array}$} & $\begin{array}{l}\text { No strength or flexibility } \\
\text { activities }\end{array}$ & 60 & 38.0 \\
\hline & $\begin{array}{c}\text { Strengthening, once a week or } \\
\text { more }\end{array}$ & 13 & 8.2 \\
\hline & Flexibility, once a week or more & 56 & 35.4 \\
\hline & Both flexibility and strength & 29 & 18.4 \\
\hline
\end{tabular}

On BMI categorization, out of 158 females 20 were underweight, 100 had normal BMI and 38 were overweight. On RAPID ASSESSMENT OF PHYSICAL ACTIVITY I scale, out of 158 females, only $8(5.1 \%)$ females scored as sedentary lifestyle and $70(44.4 \%)$ females scored as active that showed a high level of physical activity. On RAPID ASSESSMENT OF PHYSICAL ACTIVITY II scale, out of 158 females only $13 \quad(8.2 \%)$ females performed strengthening exercise once a week or more and $60(38 \%)$ females performed no strength or flexibility activities.

\begin{tabular}{|c|c|}
\hline Variable & Mean \pm SD \\
\hline $\begin{array}{c}\text { RAPID ASSESSMENT OF PHYSICAL } \\
\text { ACTIVITY-I }\end{array}$ & $4.74 \pm 1.893$ \\
\hline $\begin{array}{c}\text { RAPID ASSESSMENT OF PHYSICAL } \\
\text { ACTIVITY-II }\end{array}$ & $1.34 \pm 1.166$ \\
\hline HPLS & $2.41 \pm .404$ \\
\hline Health responsibility & $2.21 \pm .471$ \\
\hline Nutrition & $2.23 \pm .516$ \\
\hline Spiritual growth & $2.57 \pm .558$ \\
\hline Interpersonal relationship & $2.55 \pm .537$ \\
\hline Stress management & $2.52 \pm .540$ \\
\hline
\end{tabular}

The mean value of RAPID ASSESSMENT OF PHYSICAL ACTIVITY-I was $4.74(\mathrm{SD}=1.893)$ while minimum value was 1 and maximum value was 7.The mean for RAPID ASSESSMENT OF PHYSICAL ACTIVITY-II was 1.34 $(\mathrm{SD}=1.166)$ while minimum value was 0 and maximum value was 3. The Mean value of HPLS was $2.41(\mathrm{SD}=.404)$ while minimum value was 1 and maximum value was 4 which showed females follow less health promoting behavior. Out of 6 subscales of health promoting lifestyle profile, Spiritual growth scored maximum Mean value 2.57( $\mathrm{SD}=.558)$ while Health responsibility scored lowest value $2.21(\mathrm{SD}=.471)$

Regression and correlation between Rapid Assessment of Physical Activity and Health promoting lifestyle profile

\begin{tabular}{|c|c|c|c|c|}
\hline Predictor & $\mathrm{R}$ & $\mathrm{R}^{2}$ & Adjusted $\mathrm{R}^{2}$ & Standard error of estimate \\
\hline HEALTH PROMOTING LIFESTYLE PROFILE & .065 & .004 & -.002 & 1.895 \\
\hline
\end{tabular}

ANOVA (Analysis of variance)

\begin{tabular}{|c|c|c|c|c|c|}
\hline Model & Sum of squares & Df & Mean square & F & p-value Sig \\
\hline REGRESSION & 2.404 & 1 & 2.404 & .670 & 0.41 \\
\hline
\end{tabular}

The value $\mathrm{R}=.065$ shows a poor (weak) level of prediction which shows weak correlation between level of physical activity and health promoting practices. $\mathrm{R}^{2}$ shows low $0.4 \%$ variation in the level of physical activity among females which follows health promoting behavior. Prediction of physical activity of females with health promoting practices was not statistically significant i.e. $F(1,156)=.670$, pvalue $=0.41$ which is not significant.

\section{Conclusion}

This study reasoned that Female Physiotherapy Students were less physically dynamic. They had undesirable way of life. Results uncovered that females had imperfect level of physical movement and Health advancing conduct additionally scored as low. Wellbeing obligation scored was most minimal that indicated they didn't pay consideration on their wellbeing. Wellbeing advancing practices had no impact on physical action level of females in light of the fact that there was no relationship between wellbeing advancing practices and physical action.

\section{References}

[1] Lee RL, Loke AJ. Health-promoting behaviors and psychosocial well-being of university Physiotherapy Students in Hong Kong. Public health nursing. 2005;22(3):209-20. 


\section{International Journal of Science and Research (IJSR) \\ ISSN (Online): 2319-7064}

Index Copernicus Value (2013): 6.14 | Impact Factor (2015): 6.391

[2] Al-Eisa ES, Al-Sobayel HI. Physical activity and health beliefs among saudi women. J. of nutrition and metabolism. 2012;2012.

[3] Sajwani RA, Shoukat S, Raza R, Shiekh MM, Rashid Q, Siddique MS, et al. Knowledge and practice of healthy lifestyle and dietary habits in medical and nonmedical Physiotherapy Students of Karachi, Pak. J. of the Pakistan Medical Association. 2009;59(9):650.

[4] Kann L, Kinchen S, Shanklin SL, Flint KH, Kawkins J, Harris WA, et al. Youth risk behavior surveillanceUnited States, 2013. MMWR Surveill Summ. 2014;63(Suppl 4):1-168.

[5] Sakamaki R, Toyama K, Amamoto R, Liu C-J, Shinfuku N. Nutritional knowledge, food habits and health attitude of Chinese university Physiotherapy Students-a cross sectional study-. Nutrition J. 2005;4(1):4.

[6] Lobelo F, Duperly J, Frank E. Physical activity habits of doctors and medical Physiotherapy Students influence their counselling practices. British J. of sports medicine. 2009;43(2):89-92.

[7] Teixeira PJ, Carraça EV, Markland D, Silva MN, Ryan RM. Exercise, physical activity, and self-determination theory: a systematic review. Int J Behav Nutr Phys Act. 2012;9(1):78.

[8] Rodríguez DA, Cho G-H, Evenson KR, Conway TL, Cohen D, Ghosh-Dastidar B, et al. Out and about: association of the built environment with physical activity behaviors of adolescent females. Health \& place. 2012;18(1):55-62.

[9] Neumark-Sztainer D, Paxton SJ, Hannan PJ, Haines J, Story M. Does body satisfaction matter? Five-year longitudinal associations between body satisfaction and health behaviors in adolescent females and males. J. of Adolescent Health. 2006;39(2):244-51.

[10] Walker S, Sechrist K, Pender N. The health-promoting lifestyle profile II. 1995.

[11] Vega-López S, Chavez A, Farr KJ, Ainsworth BE. Validity and reliability of two brief physical activity questionnaires among Spanish-speaking individuals of Mexican descent. BMC research notes. 2014;7(1):29.

\section{Author Profile}

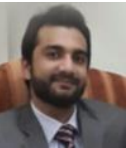

Fahad Tanveer is Senior Lecturer, Azra Naheed Medical College, Department of Physical Therapy, Main Raiwind Road, Lahore

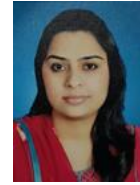

Sana Shahid is Demonstrator, The University of Lahore, Department of Physical Therapy, Main Raiwind Road, Lahore 